\title{
A Study on Using Contraception in Dhaka City: A Scenario from Slum Area
}

ISSN: 2311-8636 (Print)

ISSN: 2312-2021 (Online)

DOI prefix: 10.18034/ajhal

Licensed:

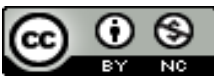

Source of Support: Nil

No Conflict of Interest: Declared

*Email for correspondence: awalkabir@pust.ac.bd

\section{Md. Awal Kabir ${ }^{*}$, Monirul Islam², Md. Yahia Bapari ${ }^{3}$}

${ }^{1}$ Chairman, Dept. of Social Work, Pabna University of Science \& Technology, Pabna, BANGLADESH

${ }^{2}$ Lecturer, Dept. of Social Work, Dhaka Mohanagar Mohila College, Dhaka, BANGLADESH

${ }^{3}$ Lecturer, Dept. of Economics, Pabna University of Science \& Technology, Pabna, BANGLADESH

\section{ABSTRACT}

Family planning programs are still considered to be an important way to control the rapid population growth of Bangladesh. In this context, a study has conducted to unveil the scenario of using contraception in slum area of Dhaka City. Sample survey has used as a main method of research in this study. The study found that the slum women are using different types of contraceptive like as pill, IUD,

injection, condom, etc. As a result of these uses they also suffered different types of problems including weakness, increasing weight, vomiting, menstrual problems, etc. In this study, it also found that anemia, urine problem, labor pain are common problems faced by women during pregnancy. In this regard, malnutrition problems also compounded this situation. It is remarkable that hospital, clinic and huts are the place of birth of their children. Radio, television, newspaper and other mass media should come forward to encourage male participation and responsibility in contraceptive method choice. Appropriate policy should develop by considering the related factors to increase contraceptive knowledge among grass root level of Bangladesh.

Key Words: Contraception, Slum, Family Planning, Women

\section{INTRODUCTION}

In developing countries, the uses of contraceptives are increasing, and some countries like Bangladesh, Thailand and Indonesia have achieved notable success (Greenspan A, 1991). The selection of contraceptive methods depends on psychological, social and cultural factors (i.e. perceptions of contraception and existing social norms about this culture) (Olaitan,2011).More-over, the use of contraception is dependent on the knowledge and attitudes of males towards modern contraception (e.g. contraceptive pills, implants, injectable, intrauterine device, male and female condoms, vasectomy, tubal ligation, etc.). The partner's disapproval of using is associated with more use of traditional methods (e.g. coitus interrupts, periodic abstinence, etc.). A study in Bangladesh showed that couples who had more than four children were 2.29 times more likely to use modern contraceptives (Kamal, 2013). 
In Bangladesh, during the late seventeen, the government introduced the services of female field workers to provide doorstep services to women in reproductive ages and provide contraceptive pills and condoms free of charge. Additionally, they provided motivation and counselling services for the people. Under Health and Population Sector Program (HPSP), static clinics with Essential Services Package (ESP) were introduced in the community. This involved one community clinic serving a catchment population of around 6000, and selective household visits by female workers to be made once a week. (MOHFW 1997).Additionally, instead of offering family planning services alone, these clinics were devised to improve national rates of neonatal mortality, maternal mortality and infant mortality. Demographers were concerned that this shift would necessitate a major change in behavior pattern of the women in Bangladesh. Especially, because the mobility of women is restricted in this society where practice of purdah is very common (Cleland et al.1996).

Dhaka is one of the most populated city in the world that known as mega city. Every day a number of people come in Dhaka for getting a better income opportunity. But unfortunately in most cases they don't get there desirable opportunity. As a result most of them are insisted to do odd jobs and living in slum areas, about half of migrated people are women. Those women are facing deplorable situation because of their socio-economic vulnerability. Most of women are deprived all types of basic needs and minimum facilities of a better life. Moreover there busy with three livelihood. So they are ignoring and not so conscious about their reproductive health though it is very important to live a healthy life for their ignorance a huge number of health problem are existing in slum area such as maternal mortality, infant mortality, malnutrition, increasing risk of STD including HIV/AIDS, unsafe abortion, injuries, disability, infertility, tendency to give birth more children.

From that perspective it can be said that it is a burning issue related to sustainable development and the high time to take effective programs consistent with our sociocultural context as existing programs are not so effective. Now to start new programs highlighting slum people especially women concern authority needs latest information. So if we can present the real situation of the reproductive health of slum women. It will be help full for policy maker, social worker and concern authority to formulate policy, plan and programs. Furthermore in recent time policy maker are giving preference on indigenous skill and knowledge to solve problems and sustainable development.

\section{OBJectives OF THE Study}

The prime objective of the study is to find out information regarding the uses of contraceptive of slum women in Dhaka city. Specific objectives of the study are depicted below:

- To know the socio-economic profile of the slum women;

- To explore the uses of different kinds of contraceptives of slum women;

- To explain the problems of slum women due to using contraception; and

- To collect information on pregnant women's caring.

\section{Conceptual Clarification}

Contraception: Contraception (birth control) is a process to prevent pregnancy by interfering with the normal process of ovulation, fertilization, and implantation.

Slum: A very poor and crowded area, especially of a city where the houses are in an extremely unhygienic state \& the living conditions are very low.

Women: Women are an adult female human being in the age group of 15-49. 


\section{Methodology OF THE Study}

The present research is a quantitative sample survey. This research is mainly a social research to exploit facts. Sample survey has used as a research method .This research based on kamla PUR, karwan Bazar and kamrangi Chor slum area in Dhaka city. All the women of a slum area in Dhaka city are the population of the study, and each woman is the unit of analysis in this study. Purposive sampling technique used in the present study. Firstly three slums of Dhaka city was selected purposively. There was Kamla PUR slum, Karwan Bazer slum \& kamrangi chor slum. Secondly, 20 women (who has at least one children) from each slum was selected purposively. In this research data has been collected through a primary source. Firstly the collected data has been edited. Then it has been classified according to its characteristics. Various statistical methods have used to analysis data. The collected data has processed after essential checking, re-checking, and editing. Quantitative data analyzed through various statistical procedures. Finally, data has presented in the tabular and graphical form.

\section{LIMITATIONS OF THE STUDY}

In spite of having cordial desire we cannot perform well due to some problems and limitations. Some main restrictions we have faced in the way of conducting the research. For the limitation of time, it was not possible to collect information from others female person of the family. In this study half of the women are little educated. So, they were not aware of their condition. They were not able to give the right answer for the right question because they were failure to understand the importance of the research. Since using contraception is a sensitized issue, respondents were reluctant to provide information in many regards. After all, the research was carried out in a new field of knowledge. Besides the limitations it can be a first-hand data for the researchers who carry out similar type of investigation in future.

\section{ANALYSIS AND FINDINGS}

Table 1: Age of the Respondents

\begin{tabular}{|c|c|c|}
\hline Age & Frequency & Percentage \\
\hline $15-19$ & 7 & 11.67 \\
\hline $20-24$ & 14 & 23.33 \\
\hline $25-29$ & 22 & 36.67 \\
\hline $30-34$ & 7 & 11.67 \\
\hline $35-39$ & 4 & 6.67 \\
\hline $40-44$ & 5 & 8.33 \\
\hline $45-49$ & 2 & 3.33 \\
\hline
\end{tabular}

Table 1 represents the percentage of the respondents by age group. The majority of the respondents are $(36.67 \%)$ are within $25-29$ years. Second most respondents $(23.33 \%)$ are within 20-24 years. A very negligible percentage of the respondents are $6.67 \%$ within $35-39$ years. And another large number of respondents (11.67\%) are within the age group of 3034 years. From the table, it can be said that most of the respondents' are young.

Table 2: Educational qualification of respondents

\begin{tabular}{|c|c|c|}
\hline Education & Frequency & Percentage \\
\hline Illiterate & 15 & 25 \\
\hline Literate & 30 & 50 \\
\hline Primary & 10 & 16.67 \\
\hline Secondary & 5 & 8.33 \\
\hline Total & 60 & 100.00 \\
\hline
\end{tabular}


Table 2 reveals that a remarkable percentage (50\%) of the respondents is literate. Second highest remarkable percentages $(25 \%)$ of the respondents are illiterate. The lowest percentage of the respondents $(8.33 \%)$ has finished secondary level of education. Here is shown that most of the respondents are literate. So it proves that literate person is more aware of their reproductive health and family planning.

Table 3: Percentage distribution of the respondents by their religion

\begin{tabular}{|c|c|c|}
\hline Religion & Frequency & Percentage \\
\hline Islam & 55 & 91.67 \\
\hline Hindu & 5 & 8.33 \\
\hline Buddhist & 0 & 0 \\
\hline Christian & 0 & 0 \\
\hline Total & $\mathrm{N}=60$ & 100 \\
\hline
\end{tabular}

Table 3 shows that the highest percentages (91.67\%) of the respondents are the follows of religion, Islam. Besides $8.33 \%$ respondents have set beliefs on religion Hindu. Which frequency is .5 but there is no answer from Christen and Buddhist. Therefore, it is the reflection as the most percentage of Muslim respondents.

Table 4: Percentage distribution of the respondents on the basis of their religion

\begin{tabular}{|c|c|c|}
\hline Occupation & Frequency & Percentage \\
\hline Housewife & 40 & 66.67 \\
\hline Day Labor & 60 & 33.33 \\
\hline Total & 60 & 100.00 \\
\hline
\end{tabular}

The table shows the nature of respondent's occupation. On the basis of profession, it is found by observation that $61.67 \%$ respondents are housewife. It shows the traditional attachment of Bangladesh women, which is closely associated with social norms \& values, rituals \& beliefs and moreover with prosperous culture. They are performing household work that has not any economic value in the view of economics. Besides 33.33\% respondents engaged in day labor. The findings indicate that the most of the women are not so rich or solvent. Because, most of them are notinvolve in income generating activities.

Table 5: Percentage distribution of the women by their Income

\begin{tabular}{|c|c|c|}
\hline Monthly Income & Frequency & Percentage \\
\hline $1500-2499$ & 7 & 11.67 \\
\hline $2500-3499$ & 12 & 20 \\
\hline $3500-4499$ & 12 & 20 \\
\hline $4500-5499$ & 11 & 18.33 \\
\hline $5500-6499$ & 8 & 13.33 \\
\hline $6500-7499$ & 8 & 13.33 \\
\hline $7500-8499$ & 2 & 3.33 \\
\hline Total & $\mathrm{N}=60$ & 100 \\
\hline
\end{tabular}

The table shows percentage of monthly income of respondents' family. Most of their income between 3000-4499 taka, which rate is $20 \%$.on the other hand a significant number of respondents income is between $5500-6499 \mathrm{Tk}$ (13.33\%) and lowest percentage is $3.33 \%$ whose income between 7500-8499. The table indicates that the incoming part between (3500-4499) is the significant portion. The table of the respondent's family income presents that most of them are poor and (7500-8499Tk) income is negligible. It also presents that they are not solvent. 
Table 6: Percentage distribution of the respondents by their marital status

\begin{tabular}{|c|c|c|}
\hline Marital status & Frequency & Percentage \\
\hline Married & 53 & 88.33 \\
\hline Divorced & 2 & 3.33 \\
\hline Rejected & 2 & 3.33 \\
\hline Widow & 3 & 5 \\
\hline Total & $\mathrm{N}=60$ & 100 \\
\hline
\end{tabular}

The table represents that a remarkable percentage $(88.33 \%)$ are married. At the same time, a little number of respondents $(3.33 \%)$ are divorced \& rejected. And the portion of a widow is $5 \%$.it is seen that most of the respondents are married.

Table 7: A Number of children of the respondents

\begin{tabular}{|c|c|c|}
\hline Number of children & Frequency & Percentage \\
\hline $1-3$ & 38 & 63.33 \\
\hline $3-5$ & 19 & 31.67 \\
\hline $5-7$ & 2 & 3.33 \\
\hline $7-9$ & 1 & 1.67 \\
\hline Total & $\mathrm{N}=60$ & 100.00 \\
\hline
\end{tabular}

The table 7 shows that a notable segment $(63.33 \%)$ of the respondents has more than one child (1-3). Besides a remarkable percentage of respondents have more than two children (3-5) which formed $31.67 \%$. From the table, it can be said that most of the women are conscious about family planning.

Table 8: Types of using family planning methods by the respondents

\begin{tabular}{|c|c|c|}
\hline Family planning methods & Frequency & Percentage \\
\hline Pill & 10 & 16.67 \\
\hline Injection & 28 & 46.67 \\
\hline IUD & 2 & 3.33 \\
\hline Condom & 3 & 5.00 \\
\hline Ligation & 2 & 3.33 \\
\hline Do not use & 14 & 23.33 \\
\hline Others & 1 & 1.67 \\
\hline Total & $\mathrm{N}=60$ & 100.00 \\
\hline
\end{tabular}

Table 8 represents that the rate of using family planning method of respondents. The highest percentages of the respondents have taken the injection which formed $(46.67 \%)$. Another remarkable portion of the respondents $(16.67 \%)$ have taken the pill. Besides significant number of women $(23.33 \%)$ does not use family planning method.

Table 9: Physical problems after using family planning method

\begin{tabular}{|c|c|c|}
\hline Physical problems & Frequency (N-60) & Percentage \\
\hline Weakness & 30 & 50.00 \\
\hline Weight Increasing & 20 & 33.33 \\
\hline Vomiting & 15 & 25.00 \\
\hline A Headache & 17 & 28.33 \\
\hline Menstruation problem & 9 & 15.00 \\
\hline No problems & 18 & 30.00 \\
\hline
\end{tabular}

*More than one response 
Table 9 reveals that most of the respondents (30\%) did not face any problem during the using period of family planning method. But $28.33 \%$ of the total respondents faced problem by Headache due to using family planning method. In this regard, problems in menstruation $(15.00 \%)$, weakness $(50.00 \%)$, weight increasing $(33.33 \%)$ of total figure. The finding indicates that some of the respondents did not face problems during the using period of contraceptives because of the awareness of their family but significant of them faced many complexities.

Table 10: Percentage distribution of decision maker about taking contraceptives

\begin{tabular}{|c|c|c|}
\hline Decision maker & Frequency & Percentage \\
\hline Own decision & 34 & 73.91 \\
\hline Both decision & 11 & 23.91 \\
\hline Doctor & 1 & 2.17 \\
\hline Total & $\mathrm{N}=46$ & $100 \%$ \\
\hline
\end{tabular}

Table 10 represents that the highest percentages of the respondents have taken family planning method according to their decision, then, both (Husband and wife) decision (23.91) and Doctor's decision (2.17\%). The table shows that most of the women are afford to decide about taking contraceptives.

Table 11: Opinion of respondents to change family planning method

\begin{tabular}{|c|c|c|}
\hline Opinion & Frequency & Percentage \\
\hline Yes & 36 & 43.48 \\
\hline No & 24 & 56.52 \\
\hline Total & 60 & $100 \%$ \\
\hline
\end{tabular}

The table 11 shows that most of the respondents $(56.62 \%)$ do not want to change their current family planning method. But a remarkable percentage of the total respondents $(43.48 \%)$ are interested in change their technique. This finding indicates that the respondent women are engaged in family planning method.

Table 12: Types of problems during pregnancy

\begin{tabular}{|c|c|c|}
\hline Types of problems & Frequency (N-60) & Percentage \\
\hline Permanent labor pain & 13 & 21.67 \\
\hline Dead child birth & 4 & 6.67 \\
\hline Anemia & 15 & 25.00 \\
\hline The problem in urine & 25 & 41.66 \\
\hline No problem & 30 & 50.00 \\
\hline
\end{tabular}

*More than one response

The table represents that the highest percentage of the respondents (50\%) did not faces problems during pregnancy. But a remarkable percentage $(41.66 \%)$ of the respondent's faced problems in urine. And $21.67 \%$ out of total figure suffered problems by permanent labor pain.

Table 13: Birth place of children

\begin{tabular}{|c|c|c|}
\hline Birth Place & Frequency & Percentage \\
\hline Hospital & 8 & 13.33 \\
\hline Clinic & 3 & 5.00 \\
\hline Huts & 45 & 75.00 \\
\hline Building & 4 & 6.67 \\
\hline Total & 60 & 100.00 \\
\hline
\end{tabular}


The table shows that most of the respondents' $(75.00 \%)$ children birth place child in huts, then hospital $(13.33 \%)$, building $(6.67 \%)$ and clinic $(5.00 \%)$. The findings indicate that majority of the respondents gave birth their children in made of mud without modern medical facilities.

Table 14: Food habits during pregnancy

\begin{tabular}{|c|c|c|}
\hline Types of Food & Frequency & Percentage \\
\hline Vegetables & 45 & 75.00 \\
\hline Fruits & 5 & 8.33 \\
\hline Meat-fish & 10 & 16.67 \\
\hline & $\mathrm{N}=60$ & 100.00 \\
\hline
\end{tabular}

The table reveals that most of the respondents $(75.00 \%)$ took vegetables during pregnancy and second highest percentage of the respondents $(16.67 \%)$ took fish and meat during pregnancy. The table shows that majority of the respondents did not get balanced diet during pregnancy, and less number of respondents took balanced diet.

\section{Discussion AND CONCLUSION}

By the Millennium Development Goals (MDGs), the Government of Bangladesh (GOB) has disclosed its plan to reduce maternal mortality by $75 \%$ by 2015 . The Ministry of Health and Family Welfare launched the Health Nutrition and Population Sector Program (HNPSP) in 2003, where among a few other primary objectives, reduction of the TFR is a major one. It is depend on a Sector Investment Plan (SIP) for the period of July 2003 to June 2010. The plan emphasizes to arrange a campaign to circulate information for all public health and Reproductive Health Services, the use of life-saving practices for new born care, shifting of family planning use patterns towards longer lasting method and health voucher programs. In this context, a study has conducted to unveil the scenario of using contraceptives in slum area of Dhaka City.

The study analyzed the scenario how socio-economic factors affect the use of different contraceptive methods among slum women in Dhaka city. It has found that the certain factors influence the use of modern contraceptive method of couples: educational qualification of couples, wife's involvement in earning activities, number of living children in the family, positive attitude towards modern contraceptives, higher level of knowledge on contraceptives, male's consent regarding family planning.

In family planning program, women are usually set as the target group and ignore the role of men. In traditional society where decisions are taken by men, they should be actively involved in reproductive decision of the couple. This study revealed that husband consent on family planning is connected with any kinds of contraceptives. Husband's participation in family planning is also important to those women who intend to use new contraceptives in future. We found that attitude of modern contraceptive is also associated with modern contraceptive use but it has no significant effects in choosing traditional methods. Evidence shows that positive attitude of couples towards modern contraceptive increases the likelihood of using modern contraceptive.

The study also found that the slum women are using different types of contraceptive like as pill, IUD, injection, condom, etc. As a result of these uses the also suffered different types of problems including weakness, weight increasing, vomiting, menstrual problems, etc. 
Government has strong commitment to improve maternal health care system in Bangladesh. But the health system is still weak due to the absence of strong infrastructure of public health facilities throughout the country. The latest BDHS finds that only5 \% women have had deliveries by SBA. Facilities often lack necessary equipment, supplies, drugs and contraceptives or may stock out of these necessities. The TFR is lowest among the poor and studies have found marked difference in access of health Services between the rich and the poor (CIET 2003). In this study, it also found that anemia, urine problem, labor pain are common problems faced by women during pregnancy. Malnutrition problems also compounded this situation. It is remarkable that hospital, clinic, huts are the place of birth of their children.

The extra underhand cash, which is being paid for such services, is unaffordable for the poorest and this group is lagging behind in all indicators including fertility. The BDHS also finds that among pillusers, which the most popular method are, $42 \%$ mention local pharmacies as their sources of supply as opposed to $47 \%$ citing GOB sources. Among them, $35 \%$ cite female field worker as their source. It appears that women depend on the home visits for their supply of birth control methods, their visits to the static clinics are more often for child immunization and child related morbidity (Khanum et al. 2000). The home visits by fieldworkers are still the main source of supply of pills, and condoms (NIPORT 2005).The preference for a male child and the age of the woman are obvious in all the models. Much of this has been discussed extensively in the literature. Older women (above 30) are more likely to accept sterilization and younger women are more likely to use pills and IUD/injections. Demanding male child has found to be highest in Bangladesh (Arnold 1997).However; the data finds that the couples are willing to practice contraception after one son has been born. As the number of living son's increases, the probability of being a user decreases. It is probably because the woman's age also increases and studies have found that older women in Bangladesh usually opt for traditional methods (Kamal et al. forthcoming).

In Bangladesh, the labor migrations to Middle Eastern countries have increased in the last decade. Demographers have reasons to claim that as the migrants return from the Middle East they may bring back a much more fundamentalist version of Islam, than what has been traditionally practiced in Bangladesh. The religious reason was a reason for not- use among married men surveyed in rural Pakistan. Out of a qualitative sample of 180 married men, $29 \%$ perceived that religious leaders were opposed to family planning. They also thought that religious leaders, especially in rural areas should be made part of the family planning campaigns to achieve higher influence on the people who are their followers (Ali and Ushijima 2005).A study conducted in Bangladesh by Shahjaha net al. found that men having higher income level, more education and those who access to media were more likely to be engaged in reproductive healthcare services (Shahjahan M,2013). This study reveals that men have considerable knowledge on modern birth control method. Problem of side-effects is one of the reasons for not using modern contraceptive and thus leads them to use traditional methods. Radio, television and mass media should come forward to encourage male participation and responsibility in contraceptive method choice. Appropriate policy should formulate by considering the related factors to increase contraceptive knowledge among grass root level of Bangladesh. 


\section{REFERENCES}

Bangladesh www.iub.edu.bd/chpd/publications.htm

Bapari, M., \& Joy, M. (2016). Estimation of Rice Production Function in Rajbari District, Bangladesh: an Econometric Analysis. Asian Journal Of Humanity, Art And Literature, 3(1), 99-112.

Basher, A., \& Tania, F. (2015). Knowledge and Attitudes about HIV/AIDS among the Slum Dwellers in Dhaka City. Asian Journal Of Humanity, Art And Literature, 2(3), 137-148.

CIET. 2003. The Third Service Delivery Survey, GOB and CIET, Canada.

Cleland JC, Kamal N, Sloggett A. 1996. Links between fertility regulation and education. In: Basu A, Jefferey R (eds). Female education and autonomy and fertility changes in South Asia. New Delhi, India: Sage Publications.

GOB. 1998. Programme Implementation Plan, Fifth Health and Population Programme 1998-2003, HAPP-5. Ministry of Health and Family Welfare. Dhaka: Government of the People's Republic of Bangladesh.

Greenspan A. Adding choice to the contraceptive Mix: Lessons from Indonesia., 1991. Asia-Pacific Population Policy. No 19. Honolulu: Population Institute of East-West Centre.

Kamal MM, Islam MS, Jalil M., 2013. Determinants of current contraceptive use among married couples in Bangladesh: Views of males. Asian Profil: Dhaka.

Mabud MA, Akhter R. 2003. Recent shift in Bangladesh's Population Policy and Programme Strategies: Prospects and Risks in Bangladesh Population Momentum, Consequences and Policy Implications. Centre for Policy Dialogue(CPD) Pathak Shamabesh Bangladesh.

Mabud MA.2005. Population-Health Interaction Study, Working Paper -4, Centre for Health, Population and Development (CHPD), Independent University

Magadi AM, Curtis LS., 2003. Trends and determinants of contraceptive method choice in Kenya. Stud Fam Plann, Nairobi.

NIPORT. 2005. Bangladesh Demographic and Health Survey 2004 National Institute of Population Research and Training (NIPORT) Dhaka, Bangladesh; Mitra and Associates; ORC Macro Calverton, Maryland, USA.

Olaitan OL., 2011. Factors influencing the choice of family planning among couples in Southwest Nigeria.

Schoemaker J. 2005. Contraceptive Use among the Poor in Indonesia International Family Planning Perspectives. 31 (3): 106-114.

Shahjahan M, Mumu SJ, Afroz A, Chowdhury HA, Kabir R, Ahmed K., 2013. Determinants of male participation in reproductive healthcare services: a cross-sectional study.

Tania, F., \& Sultana, N. (2015). Evidence of Contraception use among the Madrasha Teachers in a Selected Area of Dhaka City. ABC Research Alert, 1(1), Bangladesh.

UNFPA. 2004. Ten years after Cairo, Egypt. 
Publish Online and Print Version Both

Online ISSN: 2312-2021

Google Scholar: https://goo.gl/eozEWi 